\title{
Prevalence of sexual activity in older Malaysian adolescents and associated factors
}

\begin{abstract}
S Maria Awaluddin ${ }^{1 *}$, Noor Ani Ahmad ${ }^{1}$, Noridah Mohd. Saleh², Tahir Aris ${ }^{1}$, Noraida Mohd Kasim ${ }^{1}$, Noor Azlin Muhammad Sapri ${ }^{3}$ and Nik Rubiah Nik Abdul Rashid ${ }^{2}$
\end{abstract}

${ }^{*}$ Correspondence: smaria@moh.gov.my

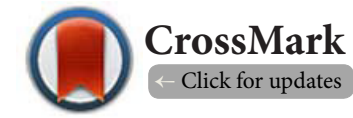

${ }^{1}$ Institute for Public Health, Ministry of Health Malaysia, Malaysia.

${ }^{2}$ Family Health and Development Division, Ministry of Health Malaysia, Malaysia.

${ }^{3}$ The National Population and Family Development Board, Ministry of Women, Family and Community Development, Malaysia.

\begin{abstract}
Background: Unprotected sexual activity predisposes adolescents to serious consequences later in life. This study aimed to identify the risks and protective factors associated with sexual activity in Malaysian adolescents aged 18 to 19 years.

Methods: Data from a health screening program among adolescents conducted in 2010 were analyzed. A total of 21,438 unmarried adolescents responded to this topic using a self-administered non-anonymous validated questionnaire.

Results: Among the participants, 54.5\% were males and 45.5\% were females. Ethnicities included $66.2 \%$ Malays, 20.7\% Chinese, 7.2\% Indians and 5.9\% other ethnicities. Most of the respondents (97.1\%) reported having a secondary level of education. The overall prevalence of sexual activity in older adolescents was $6.4 \%$ (8.9\% among males and 3.6\% among females). In a multivariate logistic regression model, sexual activity was positively associated with pornographic viewing (adjusted odds ratio [aOR]: 2.55; 95\% confidence interval [CI]: 2.01-3.22), risky behavior (aOR: 2.62; 95\%CI: 2.11-3.25), anti-social behavior (aOR: 2.44; 95\%CI: 2.06-2.90), female (aOR: 2.24; 95\%CI: 1.76-2.85), history of abuse (aOR: 1.81; 95\%CI: 1.462.24), low religiosity (aOR: 1.71; 95\%CI: 1.30-2.26) and masturbation (aOR: 1.34; 95\%CI: 1.07-1.68).

Conclusions: A comprehensive intervention program should be developed to target this at-risk group to prevent the spread of sexually transmitted diseases and criminal abortion.

Keywords: Sexual activity, risky behavior, pornographic viewing, Malaysian, adolescents
\end{abstract}

\section{Introduction}

Adolescents who engaged in unprotected sexual activity are at higher risk of contracting sexual transmitted infections such as HIV infections, having unwanted pregnancies and unsafe abortions and experiencing other psychosocial problems [1-3]. Various studies have suggested a wide range of sexual activity prevalence rates, with the highest reaching nearly 50\% [4-6].

Several surveys were conducted in Malaysia to identify the national prevalence of ever-had sex among adolescents. The 1996 National Health Morbidity Survey II revealed that $1.8 \%$ of adolescents had engaged in sexual activity [7]. A 2001 school-based study polling adolescents aged 12 to 19 years in Negeri Sembilan reported a prevalence of 5.4\% [8]. Another school-based study in a more urbanized state in Pulau Pinang investigating 15 to 20 -year-old adolescents reported a prevalence of $12.6 \%$ [9].

Many health risks and complications secondary to unprotected sexual activity among adolescents have been documented by the World Health Organization (WHO) [1,2], for which interventions should be implemented promptly. The initial step is to identify the risk and protective factors, as discussed by previous studies $[10,11]$. Sexual activity is positively associated with pornographic viewing, as shown in previous studies from Singapore and China $[12,13]$. Few studies have revealed its association with smoking, alcohol and drug abuse, which are also considered risky behaviors or substance abuse $[8,12]$. History of being abused and anti-social behaviors indicated a higher risk of engaging in sexual activity [12]. Those who had

(c) 2015 Awaluddin et al; licensee Herbert Publications Ltd. This is an Open Access article distributed under the terms of Creative Commons Attribution License (http://creativecommons.org/licenses/by/3.0). This permits unrestricted use, distribution, and reproduction in any medium, provided the original work is properly cited. 
Awaluddin et al. Journal of Public Health Aspects 2015,

a low level of religiosity were more prone to sexual activity [14]. Masturbation was also associated with adolescent sexual activity [13].

Most of the global data were based on studies conducted in the United States and Sub-Saharan countries, where there are many differences in social environments and local culture and in economic and urbanization status compared to Malaysia. This study only focused on older adolescents, as previous surveys observed a wide range of ages, from early adolescents to young adults. This study aimed to determine the prevalence of sexual activity in older adolescents and to examine the most common risk factors associated with this group in Malaysia.

\section{Methods}

\section{Sampling}

This cross-sectional study used secondary data from an adolescent health screening study that was conducted from May to December in 2010 in older adolescents who had participated in a youth program. The respondents were randomly selected through a computerized process using their Malaysian identity cards. There were three sessions during the year 2010, in which the first and second sessions consisted of adolescents who had just completed their secondary school. The third session consisted of those who were school dropouts and youths who already had jobs. The respondents were those who attended either one of the three sessions during the year 2010 in 80 centers nationwide. The health screening form was a validated, non-anonymous questionnaire routinely used in adolescent health clinics under the Ministry of Health [15]. The health screening program was conducted as a part of health services provided to the participants in the first two weeks of enrollment in the program. The adolescent health screening form consists of socio-demographic questions and the previous medical history of the respondent and their family. The main part of the form assesses risk factors in nutrition; physical activity; and reproductive, sexual and mental health. Biometric measurements and simple laboratory investigations were performed to complete the health screening. For the purpose of this article, only adolescents aged 18 to 19 years were included. Those who were not in this age range, refused to answer the questionnaires or were married were excluded from this study.

The ethical approval for this survey was granted by the Medical Research Ethics Committee, Ministry of Health, Malaysia. Written consent was obtained from the respondents. All of the information was kept confidential. Confidentiality was also assured on the front page of the health screening form.

\section{Variable definitions}

Sexual activity: Had engaged in penetrating sexual intercourse at least once in their lifetime.

Pornographic viewing: Read or viewed pornographic materials. Masturbation: Stimulated him/herself sexually.
Risky behavior: Smoked cigarettes/tobacco, consumed alcohol and used drugs.

Anti-social behavior: Had ever been involved in bully and fight. History of abuse: Had ever been abused physically or sexually. Religiosity: Answered "yes" to the question "religion is important or very important in life".

\section{Data analysis}

Data were analyzed using Statistical Package for the Social Sciences (SPSS) software, version 21(SPSS Inc., Chicago). Descriptive statistics were used to calculate the estimated prevalence of sexual activity in adolescents and socio-demographic profiles of the respondents. The Chi square test was used to determine the statistically significant differences between variables. Finally, all variables of interest were included in the multivariate logistic regression model. The findings were presented as adjusted odd ratios(aORs) with $95 \%$ confidence intervals (Cls), and a p-value $<0.05$ was considered significant.

\section{Results}

The total sample (21,438 unmarried older adolescents) consisted of $11,676(54.5 \%)$ males and $9762(45.5 \%)$ females. In terms of ethnicity, there were $66.2 \%$ Malays, $20.7 \%$ Chinese, $7.2 \%$ Indians and $5.9 \%$ other ethnicities, which reflected the ethnic breakdown of the Malaysian population based on the 2010 National Census. The response rate to the question "have you ever had sexual intercourse?" was $71.7 \%$ (Tables 1 and 2 ).

Table 1 shows the details of the socio-demographic profiles of the respondents. The prevalence of premarital sexual intercourse was $6.4 \%$ ( $8.9 \%$ among males and $3.6 \%$ among females). The difference between the male and female proportions of sexual activity was statistically significant $(p<0.001)$. There were statistically significant differences in sexual activity in terms of ethnicity, level of education, pornographic viewing, masturbation, risky behavior, history of abuse, anti-social behavior and level of religiosity. Of the total respondents, nearly half were involved in risky behaviors (smoking, alcohol use and drug abuse), and $15.5 \%$ were engaged in anti-social behaviors (bullying and fighting) (Table 3 ).

The multivariate logistic regression model retained the following variables: pornographic viewing, risky behaviors, anti-social behaviors, female, history of abuse, ethnicity, low religiosity and masturbation. There was no association between sexual activity in older adolescents and level of education. Sexual activity in older adolescents was positively associated with pornographic viewing (aOR: $2.55 ; 95 \% \mathrm{Cl}: 2.01-3.22$ ), risky behavior (aOR: 2.62; 95\%Cl: 2.11-3.25), anti-social behavior (aOR: 2.44 ; 95\%Cl: $2.06-2.90$ ), female gender (aOR: 2.24 ; 95\%Cl: 1.76-2.85), history of abuse (aOR: $1.81 ; 95 \% \mathrm{Cl}: 1.46-2.24)$, low religiosity (aOR: $1.71 ; 95 \% \mathrm{Cl}: 1.30-2.26)$ and masturbation (aOR: 1.34; 95\%Cl: 1.07-1.68) (Figure 1).

\section{Discussion}

The prevalence of ever-had sex among older adolescents in 
Awaluddin et al. Journal of Public Health Aspects 2015,

http://www.hoajonline.com/journals/pdf/2055-7205-2-1.pdf

doi: 10.7243/2055-7205-2-1

Table 1. Socio-demographic profiles of the respondents.

\begin{tabular}{lll}
\hline Variables & n & Percentage(\%) \\
\hline Gender & & \\
\hline Male & 119676 & 54.5 \\
Female & 9762 & 45.5 \\
\hline Ethnicity & & \\
\hline Malay & 14142 & 66.2 \\
Chinese & 4421 & 20.7 \\
Indian & 1546 & 7.2 \\
Others & 1264 & 5.9 \\
\hline Level education & & \\
\hline Primary & 486 & 2.4 \\
Secondary & 20087 & 97.1 \\
Tertiary & 109 & 0.5 \\
\hline Pornographic viewing & & \\
\hline Yes & 7820 & 39.5 \\
No & 11966 & 60.5 \\
\hline Masturbation & & \\
\hline Yes & 1105 & 5.8 \\
No & 17827 & 94.2 \\
\hline Sexual activity & & \\
\hline Yes & 14586 & 28.5 \\
No & 978 & 71.5 \\
\hline Risky behaviour & 14383 & 93.6 \\
\hline Yes & 5727 & 47.3 \\
No & 6373 & 52.7 \\
\hline Antisocial behaviour & & \\
\hline Yes & & \\
No & & \\
\hline History of abused & & \\
\hline No & & \\
\hline Now religiosity & & \\
\hline & & \\
\hline & & \\
\hline
\end{tabular}

Note: Subtotal are not consistent because of missing data.

this survey was $6.4 \%$. The prevalence varied among the local studies conducted in different states of Malaysia (5.4\% in Negeri Sembilan, $12.6 \%$ in Pulau Pinang and $4.6 \%$ in Selangor). The variation in the prevalence was due to the differences in the target age group in each study; the age groups were 12 to 19 years and 15 to 20 years and older and consisted of respondents mostly aged 18 years $[8,9,16]$. Additional possible causes for the variation could be due to characteristics of the respondents, method of conducting the survey, local culture, urbanization status and year of conducting the survey $[4,7,17]$. This study revealed several risk factors that were positively
Table 2. Bivariate analyses of factors associated with sexual activity in older malaysian adolescents.

\begin{tabular}{|c|c|c|c|}
\hline \multirow[t]{2}{*}{ Variables } & \multicolumn{2}{|c|}{ Sexual activity } & \multirow[t]{2}{*}{ P-value } \\
\hline & Yes n (\%) & No n (\%) & \\
\hline \multicolumn{4}{|l|}{ Gender } \\
\hline Male & $715(8.90)$ & $7322(91.10)$ & -- \\
\hline Female & $263(3.60)$ & $7061(96.41)$ & $<0.001$ \\
\hline \multicolumn{4}{|l|}{ Ethnicity } \\
\hline Malay & $618(6.23)$ & 9307 (93.77) & -- \\
\hline Chinese & $264(7.95)$ & 3057 (92.05) & -- \\
\hline Indian & $35(3.19)$ & $1063(96.81)$ & -- \\
\hline Others & $60(6.17)$ & $912(93.83)$ & $<0.001$ \\
\hline \multicolumn{4}{|c|}{ Level education } \\
\hline Primary & $42(14.33)$ & $251(85.67)$ & -- \\
\hline Secondary & $889(6.14)$ & $13794(93.86)$ & -- \\
\hline Tertiary & $7(8.86)$ & $74(91.14)$ & $<0.001$ \\
\hline \multicolumn{4}{|c|}{ Pornographic viewing } \\
\hline Yes & $702(12.02)$ & $5137(88.98)$ & -- \\
\hline No & $249(2.73)$ & $8876(97.27)$ & $<0.001$ \\
\hline \multicolumn{4}{|c|}{ Masturbation } \\
\hline Yes & $534(12.86)$ & $3620(87.15)$ & -- \\
\hline No & $410(3.82)$ & $10311(96.18)$ & $<0.001$ \\
\hline \multicolumn{4}{|c|}{ Risky behavior } \\
\hline Yes & $707(18.04)$ & $3211(81.96)$ & -- \\
\hline No & $223(4.86)$ & $4365(95.14)$ & $<0.001$ \\
\hline \multicolumn{4}{|c|}{ History of abused } \\
\hline Yes & $180(17.01)$ & $878(82.99)$ & -- \\
\hline No & $713(5.25)$ & $12860(94.75)$ & $<0.001$ \\
\hline \multicolumn{4}{|c|}{ Antisocial behavior } \\
\hline Yes & $434(19.52)$ & $1789(80.48)$ & -- \\
\hline No & $519(4.05)$ & $12279(95.94)$ & $<0.001$ \\
\hline \multicolumn{4}{|c|}{ Low religiosity } \\
\hline Yes & $108(12.56)$ & $752(87.44)$ & $<0.001$ \\
\hline No & $767(5.7)$ & $12611(94.27)$ & -- \\
\hline
\end{tabular}

Note: Subtotal are not consistent because of missing data.

associated with sexual activity in adolescents. Pornographic viewing was strongly associated with sexual activity in adolescents. A similar association was noted in a study conducted in Selangor state in teenagers aged 18 years [16]. A case-control survey conducted in Singapore among sexually active adolescents aged 14-19 years revealed a strong association with pornographic viewing (aOR 5.82 in males and 2.05 in females) [12]. Another study conducted in the southeastern United States revealed that adolescents who view pornographic materials had engaged in sexual activity (aOR 1.74 in males and 1.50 in females) [18]. The survey in Tehran used different 
Awaluddin et al. Journal of Public Health Aspects 2015,

http://www.hoajonline.com/journals/pdf/2055-7205-2-1.pdf

doi: $10.7243 / 2055-7205-2-1$

Table 3. Multivariate analyses of factors associated with sexual activity in older malaysian adolescents.

\begin{tabular}{|c|c|c|c|c|c|}
\hline Variables & $\begin{array}{l}\text { Crude OR } \\
(95 \% \mathrm{CI})\end{array}$ & Adjusted wald test & df & $\begin{array}{l}\text { Adjusted } \mathrm{OR}^{\dagger} \\
(95 \% \mathrm{CI})\end{array}$ & P-value \\
\hline \multicolumn{6}{|l|}{ Gender } \\
\hline Male & 1 & -- & 1 & 1 & -- \\
\hline Female & $0.38(0.33-0.44)^{\star}$ & 38.95 & 1 & $2.24(1.76-2.85)^{*}$ & $<0.01$ \\
\hline \multicolumn{6}{|l|}{ Ethnicity } \\
\hline Malay & 1 & 10.36 & 3 & 1 & 0.02 \\
\hline Chinese & $1.30(1.12-1.51)^{\star}$ & 4.21 & 1 & $1.30(1.05-1.60)^{\star}$ & 0.04 \\
\hline Indian & $0.50(0.35-0.70)^{\star}$ & 4.18 & 1 & $0.61(0.40-0.93)^{\star}$ & 0.04 \\
\hline Others & -- & 0.32 & 1 & -- & 0.57 \\
\hline \multicolumn{6}{|l|}{ Level education } \\
\hline Primary & 1 & 3.00 & 2 & -- & 0.22 \\
\hline Secondary & $0.39(0.28-0.55)^{\star}$ & 2.89 & 1 & -- & 0.09 \\
\hline Tertiary & -- & 0.15 & 1 & -- & 0.70 \\
\hline \multicolumn{6}{|c|}{ Pornographic viewing } \\
\hline Yes & $4.87(4.20-5.65)^{\star}$ & 61.07 & 1 & $2.55(2.01-3.22)^{*}$ & $<0.01$ \\
\hline No & 1 & -- & 1 & 1 & -- \\
\hline \multicolumn{6}{|l|}{ Masturbation } \\
\hline Yes & $3.71(3.24-4.24)^{*}$ & 6.29 & 1 & $1.34(1.07-1.68)^{*}$ & 0.01 \\
\hline No & 1 & -- & 1 & 1 & -- \\
\hline Risky behavior & & & 1 & & \\
\hline Yes & $4.31(3.68-5.04)^{*}$ & 70.22 & 1 & $2.62(2.11-3.25)^{*}$ & $<0.01$ \\
\hline No & 1 & -- & 1 & 1 & \\
\hline \multicolumn{6}{|c|}{ History of abused } \\
\hline Yes & $3.70(3.10-4.42)^{\star}$ & 26.49 & 1 & $1.81(1.46-2.24)^{*}$ & $<0.01$ \\
\hline No & 1 & -- & 1 & 1 & -- \\
\hline \multicolumn{6}{|c|}{ Antisocial behavior } \\
\hline Yes & $5.74(5.00-6.58)^{\star}$ & 94.04 & 1 & $2.44(2.06-2.90)^{*}$ & $<0.01$ \\
\hline No & 1 & -- & 1 & 1 & -- \\
\hline \multicolumn{6}{|l|}{ Low religiosity } \\
\hline Yes & $2.36(1.91-2.93)^{\star}$ & 13.20 & 1 & $1.71(1.30-2.26)^{*}$ & $<0.01$ \\
\hline No & 1 & -- & 1 & 1 & -- \\
\hline
\end{tabular}

${ }^{*} \mathrm{p}$-value $<0.05 ;{ }^{\dagger}$ Adjusted for all other variables; ${ }^{1}$ reference group

variables by asking the adolescents about access to television and found that adolescents with access to television were more likely to engage in sexual activity, with an aOR of 2.22 [19]. Currently, pornographic materials are easily available through magazines, blue films and electronic media. Exposing the adolescents to pornographic materials without proper guidance was associated with an increased tendency to engage in sexual activity $[\mathbf{2 0}, \mathbf{2 1}]$.

Risky behaviors were positively associated with adolescent sexual activity in this survey. These adolescents included those who smoked cigarettes, used alcohol and abused drugs. The association between risky behaviors and sexual activity has been well established in many studies worldwide, including in Tehran, Hanoi, Shanghai, Taipei, and Myanmar and was also

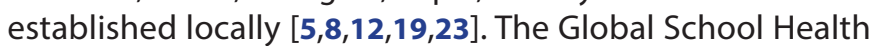
Survey (GSHS), which targeted school-going adolescents aged 12 to 17 years, also reported positive associations between risky behaviors and sexual activity in Namibia and Kenya [24,25].

Anti-social behaviors, such as bullying and fighting, were also positively associated with adolescent pre-marital sex in this study. A local study that investigated older adolescents in Selangor reported a similar association between sexual activity and anti-social behaviors [16]. A study in Singapore used variables indicating involvement in gang activities to assess anti-social behaviorsand found a positive association between these behaviors and pre-marital sex [12]. 


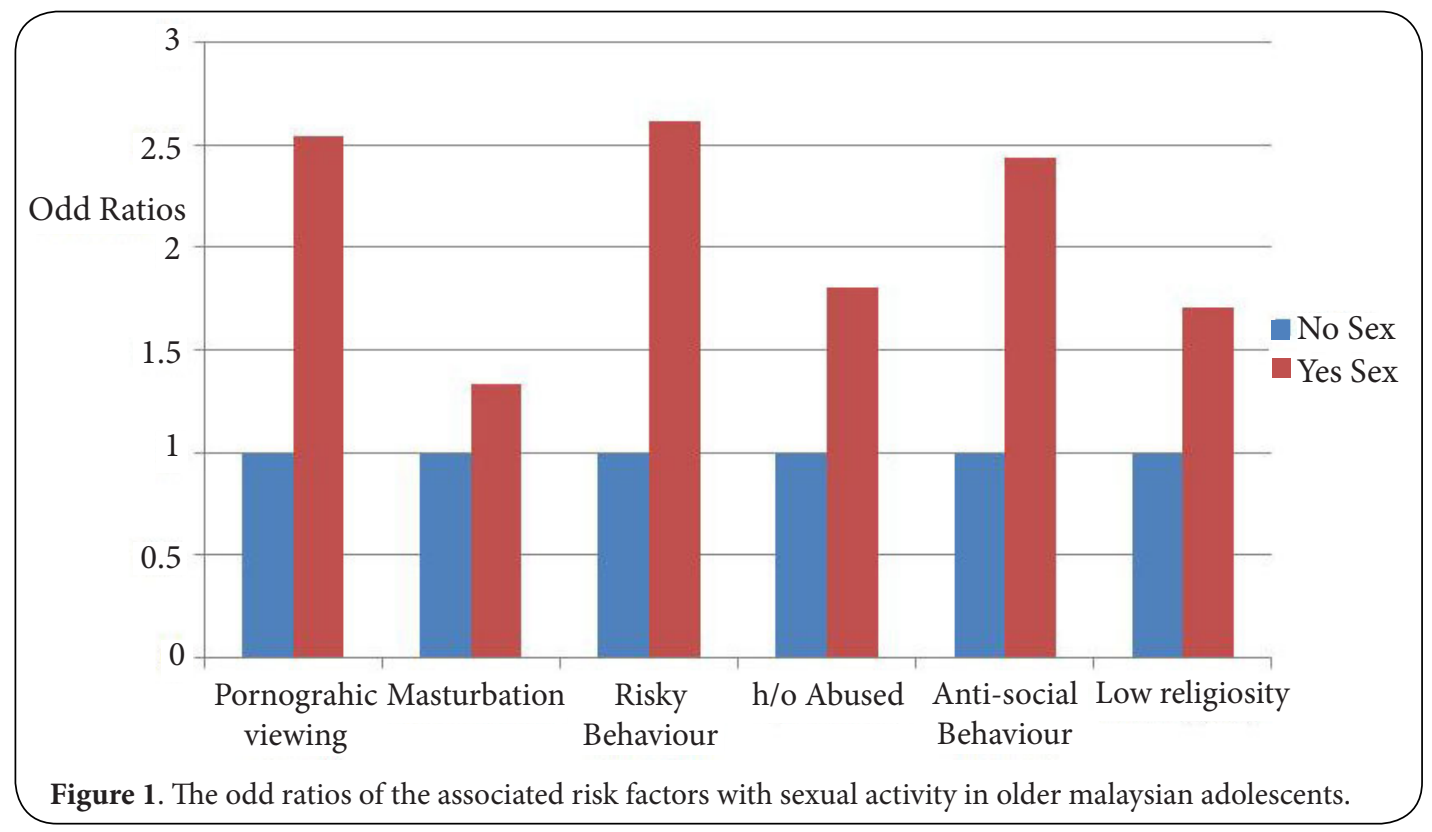

The association between gender and sexual activity indicated that females were more likely to engage in pre-marital sex. This finding contrasted those of studies conducted in New Jersey, Ethiopia, Thailand, Namibia and Kenya, where males were more likely to engage in sexual activity [24-28]. This result might suggest that females are more sincere and frank in reporting their sexual behavior. However, this unexpected finding might also be due to inadequate evaluation of additional relevant factors, such as parental characteristics, family and school connectedness, and peer and community factors.

Physical or sexual abuse increased the likelihood for sexual activity in this study (aOR 1.81). A survey in Singapore reported a similar finding, though only among female respondents [12]. Another study from Cape Town revealed that those who had a history of childhood physical abuse have earlier onset of sexual activity [29]. Those who experienced childhood sexual abuse were also at higher risk of adolescent pregnancy, and they tended to engage in high-risk sexual behavior during adulthood, including multiple sexual partners and prostitution $[30,31]$.

Religiosity was an important issue in adolescent pre-marital sexual activity. Adolescents with a low level of religiosity were more likely to engage in premarital sex in this study. Similar findings have been reported in Kenya and Tehran [14,19]. Specifically, adolescents who have a high level of religious affiliation were protected from pre-marital sex, as found in Nigeria [32]. This finding should be interpreted with caution because there was no proper scale for classifying individuals who have good religious inclinations and are well-practiced in their own religious beliefs. Furthermore, the questionnaire did not extensively explore adolescents' adherence to their own religious practices.
Adolescents who masturbate were more likely to engage in sexual activity compared to those who do not masturbate. A similar association was found in a local study conducted in Selangor state and in an international study in the United States $[16,33]$. Masturbation is another sensitive issue to be discussed openly. This factor needs to be evaluated further, as there are insufficient data to explain the possible causes for this association.

\section{Conclusion}

Sexual activity in older Malaysian adolescents was positively associated with several risks factors, such as pornographic viewing, risky behaviors, anti-social behaviors, history of abuse, low religiosity and masturbation. Females also had a positive association with adolescent sexual activity. The risk factors should be targeted with a comprehensive and effective intervention program to ensure optimum reproductive and sexual health among adolescents.

\section{Limitation}

Several limitations should be noted in this study. First, the results were based on self-reports of adolescent sexual behaviors, and the respondents may have not reported the truth, as this topic is a sensitive issue in Malaysia. Furthermore, some of the adolescents were not selected to participate in the national program and were not included in this study; therefore, their sexual behaviors cannot be assessed. The questionnaire was non-anonymous, which may have affected the respondents' answers. The possibility of recall bias was also present. Additionally, the cross-sectional design of this study prevented the determination of causal relationships. 
Awaluddin et al. Journal of Public Health Aspects 2015,

http://www.hoajonline.com/journals/pdf/2055-7205-2-1.pdf

doi: $10.7243 / 2055-7205-2-1$

\section{Recommendations}

Interventions should focus on reducing the risk factors for sexual activity. A healthy lifestyle without tobacco and alcohol and drug use should be practiced at home and should be promoted in the community. Internet services should be used wisely to improve knowledge, especially in practicing healthy lifestyles. An intervention study should be conducted to investigate those at high risk of pre-marital sex and to strengthen sex education at the school and community levels.

\section{Competing interests}

The authors declare that they have no competing interests.

\section{Authors' contributions}

\begin{tabular}{|l|c|c|c|c|c|c|c|}
\hline Authors' contributions & SA & NA & NM & TA & NMK & NMS & NN \\
\hline Research concept and design & $\checkmark$ & $\checkmark$ & $\checkmark$ & $\checkmark$ & $\checkmark$ & $\checkmark$ & $\checkmark$ \\
\hline $\begin{array}{l}\text { Collection and/or assembly } \\
\text { of data }\end{array}$ & $\checkmark$ & $\checkmark$ & $\checkmark$ & $\checkmark$ & $\checkmark$ & $\checkmark$ & $\checkmark$ \\
\hline Data analysis and interpretation & $\checkmark$ & $\checkmark$ & -- & $\checkmark$ & $\checkmark$ & -- & -- \\
\hline Writing the article & $\checkmark$ & $\checkmark$ & -- & -- & $\checkmark$ & -- & -- \\
\hline Critical revision of the article & $\checkmark$ & $\checkmark$ & $\checkmark$ & $\checkmark$ & $\checkmark$ & $\checkmark$ & $\checkmark$ \\
\hline Final approval of article & $\checkmark$ & $\checkmark$ & $\checkmark$ & $\checkmark$ & $\checkmark$ & $\checkmark$ & $\checkmark$ \\
\hline Statistical analysis & $\checkmark$ & $\checkmark$ & -- & $\checkmark$ & $\checkmark$ & -- & -- \\
\hline
\end{tabular}

\section{Acknowledgement}

We would like to express our appreciation to the Director General of Health, Malaysia, for his permission to publish this paper. We also would like to thank all of the research team members and the adolescents who voluntarily participated in this study.

Publication history

Editor: Nicola Shaw, Algoma University, Canada.

Received: 11-Oct-2014 Final Revised: 18-Nov-2014

Accepted: 29-Dec-2014 Published: 05-Jan-2015

\section{References}

1. WHO. Young people: health risks and solutions. World Health Organization. 2013. | Website

2. WHO. Adolescent pregnancy. World Health Organization. 2013. | Website

3. Low WY. Malaysian youth sexuality: Issues and challenges. J Univ Malaya Med Cent Jummec. 2009; 12:3-14. | Pdf

4. Eaton DK, Kann L, Kinchen S, Shanklin S, Ross J, Hawkins J, Harris WA, Lowry R, McManus T, Chyen D, Lim C, Whittle L, Brener ND and Wechsler $\mathrm{H}$. Youth risk behavior surveillance - United States, 2009. MMWR Surveill Summ. 2010; 59:1-142. | Article | PubMed

5. Yip PS, Zhang H, Lam TH, Lam KF, Lee AM, Chan J and Fan S. Sex knowledge, attitudes, and high-risk sexual behaviors among unmarried youth in Hong Kong. BMC Public Health. 2013; 13:691. | Article | PubMed Abstract | PubMed Full Text

6. Wang B, Li X, Stanton B, Kamali V, Naar-King S, Shah I and Thomas R. Sexual attitudes, pattern of communication, and sexual behavior among unmarried out-of-school youth in China. BMC Public Health. 2007; 7:189. | Article | PubMed Abstract | PubMed Full Text

7. Institute for Public Health, $\mathrm{MOH}$. General Findings, National Health Morbidity Survey II 1996. 1997; 2:29.

8. Lee LK, Chen PC, Lee KK and Kaur J. Premarital sexual intercourse among adolescents in Malaysia: a cross-sectional Malaysian school survey. Singapore Med J. 2006; 47:476-81. | Pdf | PubMed
9. Anwar M, Sulaiman SA, Ahmadi K and Khan TM. Awareness of school students on sexually transmitted infections (STIs) and their sexual behavior: a cross-sectional study conducted in Pulau Pinang, Malaysia. BMC Public Health. 2010; 10:47. I Article | PubMed Abstract | PubMed Full Text

10. Blum R and Mmari K. Risk and protective factors affecting adolescent reproductive health in developing countries. WHO. 2004.

11. Kirby D, Lepore $G$ and Ryan J. Sexual risk and protective factors. Factors Affecting Teen Sexual Behavior, Pregnancy Childbearing and Sexual Transmitted Disease: Which Are Important? Which Can You Change? 2005; 8 .

12. Wong ML, Chan RK, Koh D, Tan HH, Lim FS, Emmanuel S and Bishop G. Premarital sexual intercourse among adolescents in an Asian country: multilevel ecological factors. Pediatrics. 2009; 124:e44-52. | Article | PubMed

13. Chi X, Yu L and Winter S. Prevalence and correlates of sexual behaviors among university students: a study in Hefei, China. BMC Public Health. 2012; 12:972. | Article | PubMed Abstract | PubMed Full Text

14. Kabiru CW and Orpinas $P$. Factors associated with sexual activity among high-school students in Nairobi, Kenya. J Adolesc. 2009; 32:1023-39. | Article I PubMed

15. Bahagian Pembangunan Kesi hatan Keluarga Kementerian Kesihatan Malaysia, Garis Panduan Pengendalian Masalah Kesihatan Seksualdan Reproduktif Remaja di Klinik Kesihatan, Bahagian Pembangunan Kesihatan Keluarga Kementerian Kesihatan Malaysia. 2012. I Website

16. Manaf MR, Tahir MM, Sidi H, Midin M, Nik Jaafar NR, Das S and Malek AM. Pre-marital sex and its predicting factors among Malaysian youths. Compr Psychiatry. 2014; 55 Suppl 1:S82-8. | Article | PubMed

17. Eaton DK, Kann L, Kinchen S, Shanklin S, Ross J, Hawkins J, Harris WA, Lowry R, McManus T, Chyen D, Lim C, Brener ND and Wechsler H. Youth risk behavior surveillance--United States, 2007. MMWR Surveill Summ. 2008; 57:1-131. | Article | PubMed

18. Brown JD and L'Engle KL. X-Rated Sexual Attitudes and Behaviors Associated With U.S. Early Adolescents' Exposure to Sexually Explicit Media. Commun Res. 2009; 36:129-51. I Article

19. Mohammadi MR, Mohammad K, Farahani FK, Alikhani S, Zare M, Tehrani FR, Ramezankhani A and Alaeddini F. Reproductive knowledge, attitudes and behavior among adolescent males in Tehran, Iran. Int Fam Plan Perspect. 2006; 32:35-44. | Article I PubMed

20. Svedin CG, Akerman I and Priebe G. Frequent users of pornography. A population based epidemiological study of Swedish male adolescents. $J$ Adolesc. 2011; 34:779-88. | Article | PubMed

21. Owens EW, Behun RJ, Manning JC and Reid RC. The Impact of Internet Pornography on Adolescents: A Review of the Research. Sex Addict Compulsivity. 2012; 19:99-122.

22. Htay SS, Oo M, Yoshida Y, Harun-Or-Rashid M and Sakamoto J. Risk behaviours and associated factors among medical students and community youths in Myanmar. Nagoya J Med Sci. 2010; 72:71-81. | PubMed

23. Tu X, Lou C, Gao E, Li N and Zabin LS. The relationship between sexual behavior and nonsexual risk behaviors among unmarried youth in three Asian cities. J Adolesc Health. 2012; 50:S75-82. | Article I PubMed Abstract | PubMed Full Text

24. Chinsembu KC, Siziya S, Muula AS and Rudatsikira E. Prevalence and social correlates of sexual intercourse among school-going adolescents in Namibia. SAHARA J. 2008; 5:129-35. | PubMed

25. Rudatsikira E, Ogwell AE, Siziya $S$ and Muula AS. Prevalence of sexual intercourse among school-going adolescents in Coast Province, Kenya. Tanzan Health Res Bull. 2007; 9:159-63. I PubMed

26. Santelli JS, Kaiser J, Hirsch L, Radosh A, Simkin L and Middlestadt S. Initiation of sexual intercourse among middle school adolescents: the influence of psychosocial factors. J Adolesc Health. 2004; 34:200-8. I Article | PubMed

27. Seme A and Wirtu D. Premarital sexual practice among school adolescents in Nekemte Town, East Wollega. Ethiop Med J. 2008; 22:167-73. | Article 
Awaluddin et al. Journal of Public Health Aspects 2015,

http://www.hoajonline.com/journals/pdf/2055-7205-2-1.pdf

28. Peltzer K and Pengpid S. Prevalence and social correlates of sexual intercourse among school-going adolescents in Thailand. ScientificWorldJournal. 2011; 11:1812-20. | Article | PubMed Abstract | PubMed Full Text

29. Tenkorang EY and Obeng Gyimah S. Physical abuse in early childhood and transition to first sexual intercourse among youth in Cape Town, South Africa. J Sex Res. 2012; 49:508-17. | Article | PubMed

30. Lalor $K$ and McElvaney R. Child sexual abuse, links to later sexual exploitation/high-risk sexual behavior, and prevention/treatment programs. Trauma Violence Abuse. 2010; 11:159-77. | Article | PubMed

31. Noll JG, Shenk CE and Putnam KT. Childhood sexual abuse and adolescent pregnancy: a meta-analytic update. J Pediatr Psychol. 2009; 34:366-78. | Article | PubMed Abstract | PubMed Full Text

32. Fatusi $A O$ and Blum RW. Predictors of early sexual initiation among a nationally representative sample of Nigerian adolescents. BMC Public Health. 2008; 8:136. | Article | PubMed Abstract | PubMed Full Text

33. Robbins CL, Schick V, Reece M, Herbenick D, Sanders SA, Dodge B and Fortenberry JD. Prevalence, frequency, and associations of masturbation with partnered sexual behaviors among US adolescents. Arch Pediatr Adolesc Med. 2011; 165:1087-93. | Article | PubMed

\section{Citation:}

Awaluddin SM, Ahmad NA, Mohd. Saleh N, Aris T, Mohd Kasim N, Muhammad Sapri NA and Nik Abdul Rashid NR. Prevalence of sexual activity in older Malaysian adolescents and associated factors. J Public Health Aspects. 2015; 2:1

http://dx.doi.org/10.7243/2055-7205-2-1 